FORMATION Formation emploi

Revue française de sciences sociales

152 | Octobre-Décembre

Varia

\title{
Edito : des parcours sous conditions
}

Jean Frédéric Vergnies

\section{OpenEdition}

Journals

Édition électronique

URL : https://journals.openedition.org/formationemploi/8727

DOI : 10.4000/formationemploi.8727

ISSN : 2107-0946

\section{Éditeur}

La Documentation française

\section{Édition imprimée}

Date de publication : 31 décembre 2020

Pagination : 1-2

ISSN : 0759-6340

\section{Référence électronique}

Jean Frédéric Vergnies, «Edito : des parcours sous conditions », Formation emploi [En ligne], 152

Octobre-Décembre, mis en ligne le 31 décembre 2020, consulté le 04 janvier 2023. URL : http://

journals.openedition.org/formationemploi/8727 ; DOI : https://doi.org/10.4000/formationemploi.8727 


\title{
Des parcours sous conditions
}

\author{
Jean Frédéric Vergnies \\ Rédacteur en chef
}

L'analyse des parcours d'insertion a fortement progressé ces dernières décennies. Les méthodes quantitatives ont permis de catégoriser les parcours grâce à des méthodologies qui sont devenues robustes (analyse des correspondances multiples avec classification ascendante hiérarchique, carte de Kohonen, analyse harmonique, appariement optimal... $\left.{ }^{1}\right)$. Les approches qualitatives ont souligné la prégnance d'éventuels points de bifurcation, notamment grâce aux méthodes des récits de vie. Le parcours scolaire antérieur, l'origine sociale, le sexe, les territoires... sont venus progressivement compléter l'analyse des trajectoires. Il est alors utile de mieux comprendre ce qui rend possible, ou impossible, les différents parcours identifiés. Le présent numéro illustre certaines facettes de la différenciation des parcours.

Ainsi, Noémie Olympio et Valérie Germain questionnent l'influence de l'autonomie résidentielle sur les parcours étudiants. Certains ont plus de chances de décohabiter et d'intégrer des filières sélectives, quand d'autres, sous dépendance familiale et en études professionnelles, cumulent vulnérabilité scolaire et sociale.

Les écoles de production présentées ici par Pierre-Yves Bernard, Pauline David et Céline Jacob montrent que la formation peut s'opérer dans des conditions réelles de production. Cette forme de formation convenant mieux à des jeunes peu à l'aise avec la forme scolaire.

\footnotetext{
1 Jean-François Giret, "Classer, quantifier et qualifier les parcours : quelques enseignements issus de 25 années de journées du longitudinal », pp. 21-30, in Pierre-Yves Bernard, Pascal Caillaud, Sarah Ghaffari, Valérie Gosseaume, Gérald Houdeville et al.., Qualifications et parcours - Qualification des parcours. 25 èmes journées du longitudinal, Nantes, 20 et 21 juin 2019, France, Céreq échanges n 10, 379 p., https://www.cereq.fr/qualifications-et-parcours-qualification-des-parcours ou https://halshs.archives-ouvertes.fr/halshs-02356197.
} 
Gérald Houdeville, Romain Perrier et Charles Suaud analysent comment les conditions du service civique impactent fortement ses effets. Les ressources scolaires, sociales et économiques, le rôle du tuteur jouent généralement sur les aspirations professionnelles de ces jeunes en service civique.

Lors du parcours professionnel, Goucem Redjimi montre que la validation des acquis de l'expérience, bien souvent considérée par ses protagonistes comme une formation, est largement tributaire de la subjectivité des individus et des dynamiques de construction identitaire.

Si l'on s'intéresse à la formation continue, l'évolution des OPCA (Organisme paritaire collecteur agréé) peut s'avérer un atout pour la sécurisation des parcours professionnels. Anne Moysan-Louazel, Gérard Podevin et Carole Tuchszirer éclairent ici comment les OPCA, à la veille de la réforme sur la liberté de choisir son avenir professionnel, se sont adaptés pour mieux accompagner les entreprises et renforcer leur rôle d'intermédiaire du marché de l'emploi.

Au final, les parcours ne sont pas tous linéaires. Pour Ludivine Le Gros, si les reconversions professionnelles d'anciens cadres hautement qualifiés s'apparentent à une rupture qui peut être considérée comme une bifurcation biographique, les types de reconversions et les manières de se reconvertir sont fortement conditionnés par les socialisations passées. Capital social, croyances et représentations, manières d'agir incorporées en grande école influencent fortement le nouveau métier choisi.

Bonne lecture à tous. 